doctor and the US investigations by another and they were blinded of one others results.

Results Normal upper limit of the measurement between the talus and the joint capsule was evaluated from the control group. It was $3.1 \mathrm{~mm}$ (mean $+2 \mathrm{SD}$ ) and only two TC joints of the normal persons had a value above it $(4.1$ and $5.4 \mathrm{~mm})$. So, if the noechogenic space between the talus and the joint capsule was $3.1 \mathrm{~mm}$ or less, it was regarded as normal and if it was 3.2 $\mathrm{mm}$ or more, it was regarded as effusion. The clinical assessment and the US gave similar results in 35 TC joints, whereas they differed in the remaining 27 joints. The kappa coefficient between these investigations was 0.039 showing extremely poor agreement.

Conclusion These preliminary results indicate that clinical evaluation is not adequate in diagnosis of effusion and synovitis of TC joints in patients with RA. It is probable that the main source of error in this respect is tenosynovitis in the region of ankle. So, US may significantly mprove the accuracy of diagnosis of effusion and synovitis in these patients.

\section{SAT0193 PULMONARY FUNCTION TESTS IN PATIENTS WITH CONNECTIVE TISSUE DISEASES}

K Borysewicz. Department of Rheumatology, Medical Academy of Wrockaw, Wrockaw, Poland

\subsection{6/annrheumdis-2001.691}

Background In connective tissue diseases many systems and organs are involved. Pleural effusion, interstitial pneumonia, pulmonary vasculitis, rheumatoid nodules, obliterative bronchiolitis, pulmonary hypertension and pulmonary fibrosis may be found in patients with connective tissue diseases. Quality of life, effort tolerance and frequency of bronchial or lung infection depends on good pulmonary function.

Objectives The aim of this study was to examinate the spirometry indices in patients with connective tissue diseases.

Methods 80 persons: 40 with rheumatoid arthritis (RA), 11 with systemic lupus erythematosus (SLE), 8 with diffuse scleroderma, 3 with scleromyositis, 10 with ankylosing spondylitis (AS) and 8 with polymyositis were examined. The following parameters were measured: VC, ERV, FEV1, FVC, FEV1\%VC, MEF 25, 50 and 75, MEF 25/75, MVV, MEF 50\%FVC. Pulmonary function tests were done on spirometer abcPNEUMO PC in accordance with European Respiratory Society. All patients have normal blood gases values and chest X-ray.

Results In RA patients spirometric indices were in normal ranges, although the lowest values were in FEV1 and FVC. In active RA (elevated ESR and CRP) and long-term diseases maximum voluntary ventilation (MVV) was below the normal ranges. There was no ventilation disturbances in patients long-term treated with methotrexate who are in remission.

In SLE patients, all were in remission, there was no ventilation abnormalities.

AS, diffuse scleroderma and scleromyositis patients produce a restrictive spirometric defect.

The most restrictive disturbances were found in patients with active polymyositis.

MVV was the lowest values in patients with III or IV musculosceletal functional class.

There were more frequency of bronchial or pulmonary infections in patients with long-term diseases. This was not connected with immunosupressive therapy.

\section{Conclusion}

- Pulmonary function tests allow to early identification of ventilation disturbances in patients with connective tissue diseases.

- The long-term diseases have an influence on ventilation disturbances.

- Restrictive defect is the main ventilation abnormalities in connective tissue diseases.

- The most spirometric indices changes are found in active polymyositis.

- Musculosceletal functional status is important in lowering the MVV.

- Patients with connective tissue diseases have more frequent respiratory infections.

\section{SAT0194 HPLC METHOD FOR PENTOSIDINE DETERMINATION IN URINE AND SERUM}

P Spacek, M Adam. Connective Tissue Research, Institute of Rheumatology, Prague 2, Czech Republic

10.1136/annrheumdis-2001.692

Background Pentosidine (PEN) is the most known representative from the so-called AGE derivatives, whose concentration is elevated in some pathological conditions, ${ }^{1}$ (e.g. in diabetes, renal failure, osteoarthritis (OA), inflammatory diseases, etc.). PEN determination is therefore often used for characterisation of the disease activity.

Objectives The aim of this study is to elaborate precise and sensitive HPLC method for PEN determination, apply it the for evaluation in urine samples in the OA patients and in healthy controls, and to test possible correlation between urine pyridinoline ${ }^{2}$ and pentosidine.

Methods Liquid chromatograph of the firm SHIMADZU type CLASS VP version 5.0 was on line controlled by means of special software in Windows 98 milieu. Glass column Separon SGX C18, $150 \times 3 \mathrm{~mm}$ (Tessek, Prague, Czech Republic) as the stationary phase and mobile phase $0.02 \mathrm{M}$ heptafluorobutyric acid (HFBA), $0.01 \mathrm{M}$ (NH4)2SO4 with variable acetonitrile (ACN) concentration was used.

Results Pentosidine standard was synthesised utilising simple polymer analogical reaction and kindly quantified by HPLC in foreign lab. ${ }^{3}$ Variation in the reproducibility (RSD) of the HPLC alone was slightly above $1 \%$, RSD of the whole method (i.e. including sample hydrolysis and purification) was $4.44 \%$, recovery was $77 \pm 3.5 \%$, HPLC sensitivity limit was 17.6 femtomoles.

Urine PEN concentrations were determined in the OA patients $(\mathrm{N}=37$, age $66.97 \pm 9.89$ years $)$ and in control individuals $(\mathrm{N}=15$, age $30.01 \pm 8.67$ years $)$. $\mathrm{PEN}$-age dependence was eliminated by extrapolation in the sense of known measured PEN-age dependence. ${ }^{4}$ In OA PEN urine concentrations were significantly higher (almost four times) compared with healthy controls $(8.0 \pm 7.2$ vs. $2.1 \pm 0.5 \mathrm{nmol} / \mathrm{mmol}$ creat., $\mathrm{P}=$ 0.00002). Slight correlation exists between urinary pentosidine and urinary pyridinoline in OA (U-PEN $=0.0773 \% \mathrm{U}-\mathrm{PD}$ $+2.2595, \mathrm{r}=0.4$ ), probably partially evoked by immunity response of the organism due to the toxic action of PEN-containing molecular domains, ${ }^{5,6}$ sary leading to accelerated resorption kinetics and thus to the additional increasing pyridinoline level.

Conclusion Sensitive and accurate HPLC method for pentosidine determination was elaborated, optimised and quantified with 
prepared PEN standard. Urine samples of OA patients and healthy controls were evaluated. Results can probably yield useful additional information about activity of the disease.

\section{REFERENCES}

1 Sell DR, Monnier VM. J Biol Chem. 1989;264(36):21697-702

2 paèek P, Hulejová H, Adam M. J Liq Chrom Rel Technol. 1997;20(12):1921-30

3 VM Monnier, Sell DR. Case Western Reserve University, Cleveland, OH 44106

4 Takahashi M, Suzuki M, Kushida K, Miyamoto S, Inoue T. Br J Rheumatol. 1997;36:637-42

5 Vlassara H. Diabetes 1997:46(2):S19-25

6 Sullivan R. Arch Physiol Biochem. 1996;104(7):797-806

\section{SAT0195 SONOGRAPHIC AND CLINICAL EVALUATION OF THE INVOLVEMENT OF ACROMIOCLAVICULAR JOINT IN PATIENTS WITH SHOULDER PAIN}

A lagnocco, G Palombi, G Valesini. Medical Therapy, Rheumatology Unit, University "La Sapienza", Rome, Italy

\subsection{6/annrheumdis-2001.693}

Background The involvement of acromioclavicular joint (ACL) can be one of the causes of shoulder pain. Sonography studies carefully ACL and easily detects alterations of that joint. ${ }^{1}$ In particular ultrasonographic analysis makes it possible to reveal the presence of effusion and to show irregularities of the joint margins. By performing an adduction stress test clinical examination can reveal the presence of pain at the ACL. ${ }^{2}$

Objectives The aim of the present study was to examine sonographically the involvement of ACL in patients with painful shoulder and to compare the results with those obtained by clinical examination of ACL (adduction stress test).

Methods 425 patients with shoulder pain were studied. They were 282 female and 143 male; their mean age was 57.9 years (range 18-90). In 103 cases bilateral involvement was present; for this reason 528 shoulders were studied totally. Moreover both the shoulders of 198 healthy control subjects were examined. They were 109 female and 89 male and their mean age was 56.3 years (range 19-69).

Sonography of ACL was performed using a $7.5 \mathrm{MHz}$ linear transducer. In all cases ACL was examined by longitudinal scanning of the joint, with the shoulder in neutral position. Effusion was revealed when the capsule stood convex to the articular space with simultaneous appearance of hypoechoic area within the joint. ${ }^{1}$ Irregularities of the joint margins were considered present when the bone surface of the clavicle and of acromion appeared discontinuous.

An adduction stress test was performed holding the arm with the elbow and shoulder extended and then passively adducting across behind the back. ${ }^{2}$ Differences were analysed by Chi Square test.

Results Sonography of ACL showed involvement of that joint in 270 cases $(51.1 \% ; \mathrm{p}<0.0000)$. In particular effusion was present in 142 joints (26.9\%) and it was slight in 94 cases $(66.2 \%)$, moderate in $46(32.4 \%)$ and marked in $2(1.4 \%)$. Irregularities of the bone surface were found in 161 cases $(30.5 \% ; \mathrm{p}<0.0000)$. In 109 joints only effusion was present, in 128 only irregularities were found, in 33 both of the alterations were revealed.

In healthy control subjects effusion was present in only 2 cases $(0.5 \%)$, irregularities were found in 9 shoulders $(1.7 \%)$.

The adduction stress test was positive in 43 joints $(8.1 \%$; $\mathrm{p}<$ 0.0001). In particular it was positive in 34 cases with sonographic finding of effusion, in $8 \mathrm{ACL}$ with sonographic evidence of both effusion and irregularities and in 1 joint with sonographic demonstration of irregularities. Moreover, considering only the cases with joint effusion the test was positive in all the 2 cases with marked effusion, in 33 out of the 46 with moderate effusion and in only 1 out of the 94 with slight effusion.

Conclusion Sonographic study appeared to be more sensitive than clinical examination. Moreover ultrasonographic technique made it possible to identify the type of alteration showing whether it was due to the presence of inflammation (effusion) or to degenerative process (irregularities) within the joint.

Sonographic demonstration of alterations of ACL in a great percentage of cases of shoulder pain evidences the importance of this joint in the shoulder girdle pathology.

\section{SAT0196 STEREOLOGIC MEASUREMENT OF INFLAMMATORY SYNOVIAL MEMBRANE VOLUME ON MR IMAGES}

${ }^{1}$ A Savnik, ${ }^{2} \mathrm{HS}$ Thomsen, ${ }^{3} \mathrm{JR}$ Nyengaard, ${ }^{1} \mathrm{H}$ Bliddal. ${ }^{1}$ Parker Institute, University of Aarhus; ${ }^{2}$ Radiology, Herlev University Hospital, Copenhagen; ${ }^{3}$ Stereologic Research Laboratory, University of Aarhus, Aarhus, Denmark

\subsection{6/annrheumdis-2001.694}

Background Manual outlining of the synovial membrane on MR images in inflammatory joint diseases is too time consuming for clinical use.

Objectives The purpose was to introduce a less time-consuming stereologic method for measuring synovial volume by MRI in inflammatory joint diseases.

Methods Post-contrast 3-D T1-weighted turbo gradient MR images of the finger (metacarpophalangeal and interphalangeal) joints (14 joints) were acquired from 11 patients with rheumatoid arthritis $(\mathrm{n}=8)$ and reactive arthritis $(\mathrm{n}=3)$. Manually outlined volume was taken as a gold standard and compared with stereologic volume estimation on transverse $1 \mathrm{~mm}$ thick slices.

Results The total volume of 154 finger joints was estimated. A significant correlation between manual and stereologic estimations of synovial volumes was found (Spearman rho $=0.71, \mathrm{P}$ $=0.002$ ). 95\% limits of agreement were $\pm 5-6 \mathrm{ml}$ (14 finger joints per patient). The time used for volume determination in a patient varied from $1-2.5 \mathrm{~h}$ by manual outlining and from $0.5-1$ $\mathrm{h}$ by stereologic determination.

Conclusion Stereologic volume estimation can provide measures of synovial volumes comparable to the manual outlining method and is less time-consuming. Stereologic volume estimation seems to be a clinically useful method, especially if it is integrated in the MR unit?s workstation.

\section{SAT0197 INTESTINAL BEHCET'S DISEASE AND CROHN?S DISEASE: A RADIOLOGICAL COMPERATIVE STUDY}

U Korman, N Soylu, V Hamuryudan, S Kuruoglu, I Mihmanli, H Yazici. Radiology, Istanbul University Cerrahpasa Medical Faculty, Istanbul, Turkey

\subsection{6/annrheumdis-2001.695}

\section{Background}

Objectives The aim of this study was to compare the enteroclysis findings in Behcet's disease (BD) and Crohn?s disease (CD).

Methods From 1997 to 2000, seventeen patients with clinical suspicion of intestinal $\mathrm{BD}$ were examined by enteroclysis and radiological findings were compared to those seen in 50 Crohn? s cases. 